\title{
Functional Characterization of Genetic Variants in the Apical Sodium-Dependent Bile Acid Transporter (ASBT; SLC10A2)
}

\author{
Richard H. Ho ${ }^{\star}, \dagger$, Brenda F. Leake ${ }^{\dagger}$, Brad L. Urquhart ${ }^{\ddagger}$, Jamie C. Gregor ${ }^{\ddagger}$, Paul A. Dawson $\S$, \\ and Richard B. Kim ${ }^{\ddagger}$ \\ "Department of Pediatrics, Vanderbilt University Medical Center, Nashville, TN, USA \\ †Division of Clinical Pharmacology, Vanderbilt University Medical Center, Nashville, TN, USA \\ ‡Division of Clinical Pharmacology, University of Western Ontario, London, Ontario, Canada \\ §Department of Internal Medicine, Wake Forest University School of Medicine, Winston-Salem, \\ NC, USA
}

\begin{abstract}
Background and Aims-The major transporter responsible for bile acid uptake from the intestinal lumen is the apical sodium-dependent bile acid transporter (ASBT, SLC10A2). Analysis of the $S L C 10 A 2$ gene has identified a variety of sequence variants including coding region single nucleotide polymorphisms (SNPs) that may influence bile acid homeostasis/intestinal function. In this study, we systematically characterized the effect of coding SNPs on SLC10A2 protein expression and bile acid transport activity.
\end{abstract}

\begin{abstract}
Methods-SNPs in SLC10A2 from genomic DNA of ethnically-defined healthy individuals were identified using a PCR-based temperature gradient capillary electrophoresis (TGCE) system. A heterologous gene expression system was used to assess transport activity of SLC1OA2 nonsynonymous variants and missense mutations. Total and cell surface protein expression of wild-type and variant ASBT was assessed by western blot analysis and immunofluorescence confocal microscopy. Expression of ASBT mRNA and protein was also measured in human intestinal samples.
\end{abstract}

\begin{abstract}
Results-The studies revealed two nonsynonymous SNPs, 292G $>$ A and 431G $>$ A, with partially impaired in vitro taurocholate transport. A novel variant, 790A $>\mathrm{G}$, was also shown to exhibit near complete loss of taurocholate transport, similar to the previously identified ASBT missense mutations. Examination of ASBT protein expression revealed no significant differences in expression or trafficking to the cell surface amongst variants versus wild-type ASBT. Analysis of ASBT mRNA and protein expression in human intestinal samples revealed modest intersubject variability.
\end{abstract}

Conclusions-Genome sequencing and in vitro studies reveal the presence of multiple functionally relevant variants in $S L C 10 A 2$ that may influence bile acid homeostasis and physiology.

\footnotetext{
Corresponding author and requests for reprints: Richard B. Kim, MD, Division of Clinical Pharmacology, Department of Medicine, Schulich School of Medicine \& Dentistry, The University of Western Ontario, Room A-LL-152, LHSC-University Hospital, 339 Windermere Road London, ON N6A 5A5, Canada, Phone: (519) 663-3553, Fax: (519) 663-8619,

Richard.Kim@LHSC.on.ca.

CONFLICTS OF INTEREST STATEMENT

The authors have no conflicts of interest to disclose.
} 


\section{Keywords}

Biliary physiology; Bile acid metabolism; Intestinal lipid and bile acid transport

\section{INTRODUCTION}

Bile formation is critical for maintenance of intestinal lipid digestion and absorption, cholesterol homeostasis, and hepatic excretion of lipid-soluble xenobiotics $(1 ; 2)$. Bile acids comprise the major solutes in bile and serve a variety of essential physiologic roles including acting as detergents to solubilize cholesterol and dietary fats in the intestine $(3 ; 4)$ and acting as hormones to regulate gastrointestinal function and whole body metabolism by signaling through nuclear and G-protein-coupled receptors (5-9). Bile acids are efficiently reabsorbed in the small intestine and returned to the liver via the portal venous circulation and secreted back into bile, thus forming an enterohepatic circuit (2).

Members of the solute carrier 10 (SLC10) gene family play a crucial role in maintenance of the enterohepatic circulation and compartmentalization of bile acids (10). The sodiumtaurocholate cotransporting polypeptide (NTCP; SLC1OA1), expressed on the basolateral membrane of hepatocytes, mediates the uptake of bile acids from portal blood for export across the canalicular membrane into bile (10). In parallel, the apical sodium-dependent bile salt transporter (ASBT; SLC10A2), expressed on the apical membrane of ileal enterocytes, actively extracts bile acids from the intestinal lumen and facilitates their return to the liver via the portal circulation (10). In addition to ileum, ASBT is also expressed at other tissue sites that enable the enterohepatic circulation of bile acids, including the apical membrane of proximal convoluted tubule cells, large cholangiocytes, and gallbladder epithelial cells (11). In the intestine, ASBT is the major route for active bile acid uptake as evidenced by the marked bile acid malabsorption exhibited by Asbt null mice and patients with ASBT mutations (12). ASBT transports all the major species of bile acids with preference for the taurine and glycine conjugated forms (13), and no non-bile acid substrates have yet been identified for the ASBT (14).(15-17)

Considering its central role in enterohepatic circulation, inherited defects or dysfunctional regulation of the ASBT may play a role in the pathogenesis or clinical presentation of a variety of gastrointestinal disorders. Indeed, ASBT mutations are associated with Primary Bile Acid Malabsorption (PBAM; Online Mendelian Inheritance in Man: OMIM \#6013291) (13), and recent sequencing and genome wide association studies have implicated variation at the SLC10A2 locus with serum bilirubin levels and gallstone disease (18-20). In this report, we describe the systematic functional characterization of $S L C 10 A 2$ variants identified in DNA samples from a large population of ethnically-defined individuals.

\section{EXPERIMENTAL PROCEDURES}

\section{Materials}

$\left[{ }^{3} \mathrm{H}\right]$ taurocholate $(3.4 \mathrm{Ci} / \mathrm{mmol},>97 \%$ purity) and unlabeled taurocholate were purchased from PerkinElmer Life Sciences (Boston, MA). Genomic DNA from 90 European-

American, 90 African-American, 90 Chinese-American, and 90 Mexican-American healthy volunteers was purchased from Coriell Cell Repositories (Camden, NJ).

\section{Identification of Single Nucleotide Polymorphisms (SNPs) in SLC10A2}

A 22847 bp genomic sequence (NC_000013) encompassing the intron-exon boundaries for $S L C 10 A 2$ was identified from GenBank ${ }^{\circledR}$. Primer pairs to amplify the six coding exonic 
regions of SLC1OA2 were designed and PCR analysis was performed as previously described (21). SNP discovery was performed using a REVEAL temperature gradient capillary electrophoresis (TGCE) system (SpectruMedix, State College, PA) via heteroduplex separation. Variant PCR products were sequenced with an ABI 3700 DNA Analyzer (Applied Biosystems, Foster City, CA). Allele frequencies were calculated based upon the Hardy-Weinberg equilibrium. Additional variants were analyzed, including 2 mutations associated with PBAM (13), 728T $>\mathrm{C}$ and $785 \mathrm{C}>\mathrm{T}$, a mutation identified from a patient with Crohn's disease (22), 868C $>\mathrm{T}$, and a novel variant, 790A $>\mathrm{G}$, identified from a cohort of healthy subjects and patients with inflammatory bowel disease (23).

\section{Wild-type and Variant ASBT Plasmid Construction}

The open reading frame of $S L C 10 A 2$ was PCR-amplified from a human small intestinal cDNA library, subcloned into $\mathrm{pCR}^{\circledR} 2.1$-TOPO vector (Invitrogen, Carlsbad, CA), and sequenced. Point mutations were introduced into wild-type ASBT using the QuikChange site-directed mutagenesis kit (Stratagene, La Jolla, CA) and confirmed by DNA sequencing.

\section{In Vitro Transport and Protein Expression Studies}

Taurocholate transport assays were performed using transfected HeLa cells as described previously (21). To measure transport kinetics, transfected cells were incubated with the indicated concentration of $\left[{ }^{3} \mathrm{H}\right]$ taurocholate and Michaelis-Menten-type nonlinear curvefitting was carried out to obtain estimates of the maximal uptake rate $\left(V_{\max }\right)$ and the concentration at which half the maximal uptake occurs $\left(K_{m}\right)$ (Prism ${ }^{\mathrm{TM}}$, GraphPad, San Diego, CA). All experiments were carried out in duplicate on at least two experimental days.

To measure ASBT protein expression, transfected HeLa cells were lysed by sonication in HED buffer containing protease inhibitors (Complete, Roche Molecular Biochemicals). Samples were diluted with Laemmli buffer, and total cell protein was separated by SDSPAGE on $10 \%$ gels. Following transfer onto nitrocellulose membranes, blots were probed with an anti-ASBT rabbit polyclonal antibody (24) and appropriate secondary antibody. To normalize sample loading, blots were stripped with Restore Stripping Buffer (Thermo Scientific, Rockford, IL) and reprobed with anti-calnexin antibody (StressGen, Victoria, British Columbia, Canada). Protein bands were visualized using enhanced chemiluminescence.

\section{ASBT Cell Surface Protein Expression and Confocal Microscopy}

HeLa cells were transfected as described for the transport experiments. Sixteen hours posttransfection, cells were washed with ice-cold phosphate-buffered saline $\mathrm{Ca} / \mathrm{Mg}(138 \mathrm{mM}$ $\mathrm{NaCl}_{2}, 2.7 \mathrm{mM} \mathrm{KCl}, 1.5 \mathrm{mM} \mathrm{KH}_{2} \mathrm{PO}_{4}, 9.6 \mathrm{mM} \mathrm{Na}_{2} \mathrm{HPO}_{4}, 1 \mathrm{mM} \mathrm{MgCl}, 0.1 \mathrm{mM} \mathrm{CaCl}$, $\mathrm{pH}$ 7.3) and treated with a membrane-impermeable biotinylating agent (sulfo-NHS-SSbiotin, $1.5 \mathrm{mg} / \mathrm{ml}$, Pierce) at $4^{\circ} \mathrm{C}$ for $1 \mathrm{~h}$. The cells were then washed with ice-cold phosphate-buffered saline $\mathrm{Ca} / \mathrm{Mg}$ containing $100 \mathrm{mM}$ glycine and incubated for $20 \mathrm{~min}$ at $4^{\circ} \mathrm{C}$ with the same buffer. Cells were then lysed in buffer $(10 \mathrm{mM}$ Tris-base, $150 \mathrm{mM} \mathrm{NaCl}$, $1 \mathrm{mM}$ EDTA, $0.1 \%$ SDS, $1 \%$ Triton $\mathrm{X}-100, \mathrm{pH}$ 7.4) containing protease inhibitors (Complete). Following centrifugation, biotinylated protein from supernatant was precipitated using streptavidin agarose beads (Pierce). The biotinylated proteins were released by incubation of the beads with $2 \mathrm{x}$ Laemmli buffer and subjected to Western blot analysis for detection of ASBT and calnexin. Densitometric analysis was performed using ImageJ (http://rsb.info.nih.gov/ij/).

For confocal microscopy, the transiently-transfected HeLa cells were fixed for $15 \mathrm{~min}$ at room temperature in 4\% paraformaldehyde, washed with PBS, and then blocked/ permeabilized by incubation in PBS containing 10\% BSA and 0.01\% Triton X-100 for $1 \mathrm{~h}$ at 
room temperature. The cells were incubated overnight at $4^{\circ} \mathrm{C}$ with ASBT antibody (1:500) in PBS containing 5\% FBS. The cells were sequentially washed with PBS and PBS containing $10 \%$ BSA and $0.01 \%$ Triton X-100, and then incubated with fluorescent dye (Alexa Fluor 488) labeled goat anti-rabbit whole antibody (1:200) (Molecular Probes, Eugene, OR) at room temperature for $1 \mathrm{~h}$. Cells were then washed with PBS, mounted with anti-fading mounting medium (Vectashield, Vector Laboratories Inc., Burlingame, CA) and viewed by confocal immunofluorescence microscopy. HeLa cells transfected with the parent plasmid alone and cells transfected with ASBT wild-type plasmid DNA without incubation in primary antibody were used as two separate controls. Samples were imaged using a 40x, 1.3-numerical aperture F-Fluor objective lens (digital zoom 2X) of a Zeiss LSM510 META inverted confocal microscope. Image analysis and processing were performed using Zeiss LSM and Adobe Photoshop software.

\section{ASBT Expression in Human Intestinal Samples}

Pinch biopsies were collected from eighteen patients (six male and twelve female) undergoing diagnostic duodenoscopy. During the patient's routine scheduled endoscopic procedure, pinch biopsies were collected in addition to those obtained for diagnostic purposes. Biopsies were flash frozen in liquid nitrogen or stored in RNAlater (Qiagen, Valencia, CA) for protein and mRNA analysis, respectively. The study protocol was approved by the Health Sciences Research Ethics Board at the University of Western Ontario and all subjects provided written informed consent prior to the procedure.

For analysis of ASBT mRNA expression, tissue was homogenized and RNA extracted in Trizol (Invitrogen, Carlsbad, CA). The cDNA synthesis was performed with a total of 500 ng of RNA. Quantitative RT-PCR for ASBT and the enterocyte-specific marker villin was performed using a SYBR green assay (Applied Biosystems, Foster City, CA) with the following primers: ASBT, 5'-GCCCCAAAAAGCAAAGATCA-3', 5'GCTATGAGCACAATGAGGATGG-3'; villin, 5'-CTGGCAACCTTAGGGACTGG-3', 5'GTTAGCATTGAACACGTCCACTTT-3'. All samples were compared to a standard curve of the ASBT or villin amplicon for quantitative determination of copy number, and ASBT levels were normalized to expression of villin.

Samples for protein analysis were homogenized in $1 \mathrm{mM}$ EDTA, $10 \mathrm{mM}$ Tris-HCl, $\mathrm{pH} 7.4$ with protease inhibitors. For SDS-PAGE and immunoblotting, samples were diluted with Laemmli buffer, heated at $70^{\circ} \mathrm{C}$ for ten minutes, separated on 4-12\% Bis-Tris gradient gels (Invitrogen, Carlsbad, CA), and transferred onto nitrocellulose membranes. After blocking with $5 \%$ milk powder with $0.5 \%$ BSA, the membranes were probed with ASBT antibody (1:5000 dilution) followed by a goat anti-rabbit HRP conjugated secondary antibody (BioRad, Hercules, CA). To normalize sample loading, blots were incubated for 15 minutes in stripping buffer (Pierce), washed, and reprobed with anti-villin antibody (Ab-1, Thermo Scientific, Waltham, MA) and appropriate secondary antibody. Protein bands were visualized by chemiluminescence detection and images digitally captured using a Kodak $4000 \mathrm{~mm}$ Image Station (Mandel, Guelph, ON). Mean optical density of ASBT and villin were determined using Kodak Molecular Imaging Software Version 4.0 and expressed as a normalized ratio of ASBT to villin.

\section{Statistical Analysis}

Determination of the statistical differences between various group parameters was determined using either Student's $t$ test, Mann-Whitney $U$ test, analysis of variance (using Tukey-Kramer multiple comparison test), or Fisher's exact test, as appropriate. A $p$ value of $<0.05$ was taken to be the minimum level of statistical significance. 


\section{RESULTS}

\section{Single Nucleotide Polymorphisms in SLC10A2}

Six SNPs, including four nonsynonymous polymorphisms, were identified in exons 1, 2 and 3 (Table 1). In general, variants tended to be rare and ethnic-dependent, with the exception of the $511 \mathrm{G}>\mathrm{T}$ variant, found in all ethnic populations tested. The previously identified variants $728 \mathrm{~T}>\mathrm{C}, 785 \mathrm{C}>\mathrm{T}, 790 \mathrm{~A}>\mathrm{G}$, and $868 \mathrm{C}>\mathrm{T}(13 ; 19 ; 22 ; 23)$ were not identified in subjects from Coriell, but were included in the functional analyses. Figure 1 shows the amino acid positions of the SNPs analyzed in this study.

\section{Functional Analysis of ASBT Variants}

Taurocholate uptake was evaluated to determine relative transport efficiency of the ASBT variants compared to wild-type ASBT. After a 10 minute incubation, transport was significantly impaired for the $292 \mathrm{G}>\mathrm{A}$ and $431 \mathrm{G}>\mathrm{A}$ variants when compared to wild-type ASBT transport (Figure 2). Transport for the $475 \mathrm{G}>\mathrm{A}$ and $511 \mathrm{G}>\mathrm{T}$ variants were similar to wild-type ASBT. Kinetic analysis revealed that ASBT-specific taurocholate uptake was saturable with $K_{m}$ values of $1.7 \mu \mathrm{M}$ for wild-type ASBT, $4.5 \mu \mathrm{M}$ for $292 \mathrm{G}>\mathrm{A}, 2.8 \mu \mathrm{M}$ for $431 \mathrm{G}>\mathrm{A}, 1.5 \mu \mathrm{M}$ for $475 \mathrm{G}>\mathrm{A}$, and $4.2 \mu \mathrm{M}$ for $511 \mathrm{G}>\mathrm{T}$ (Figure 2). In agreement with previous reports, the rare variants $728 \mathrm{~T}>\mathrm{C}, 785 \mathrm{C}>\mathrm{T}$, and $868 \mathrm{C}>\mathrm{T}$ exhibited little taurocholate transport $(13 ; 22)$. In addition, the rare novel variant $790 \mathrm{~A}>\mathrm{G}$ also demonstrated near complete loss of taurocholate transport compared to wild-type.

\section{Expression and Plasma Membrane Targeting of ASBT Variants}

Total cellular expression levels of ASBT variants did not significantly differ in comparison to wild-type ASBT (Figure 3) when analyzed by western blot analysis. Furthermore, cell surface biotinylation experiments revealed the plasma membrane expression of each ASBT variant was similar to that of wild-type. The enrichment of cell surface proteins within these biotinylated fractions was evidenced by the lack of immunodetectable calnexin (an intracellular endoplasmic reticulum-associated protein) in the samples. To further extend our findings, we performed immunofluorescence confocal microscopy in transiently transfected HeLa cells. Utilizing a secondary fluorescent-labeled antibody, we demonstrate that wildtype ASBT was appropriately targeted to the plasma membrane when viewed laterally ( $x-y$ scans) across the cells by confocal microscopy (Figure 4). Moreover, all ASBT variants also were appropriately targeted to and expressed at the plasma membrane.

\section{ASBT Expression in Human Intestinal Samples}

Real-time semi-quantitative PCR quantification was performed using cDNA samples from 18 duodenal samples from healthy adults to evaluate for interindividual variation in ASBT expression. When normalized to the enterocyte-specific marker villin, there was modest 11-fold inter-subject variability in ASBT expression (range 0.213-2.37) (Figure 5). Thirteen samples were available for assessment of ASBT expression by western blot analysis. Excluding one sample in which protein expression could not be determined, there was $\sim 6.2$-fold variability in ASBT expression after normalization for villin expression. There was no significant correlation between SLC10A2 mRNA levels and ASBT protein expression (Figure $5, \mathrm{R}^{2}=.02, \mathrm{p}=0.64$ ).

\section{DISCUSSION}

In this report, we identified and functionally characterized nonsynonymous SNPs in SLC10A2 from genomic DNA in ethnically-defined populations. Rare dysfunctional mutations in SLC1OA2 have significant clinical consequences, as evidenced by two missense mutations from a family with PBAM, an intestinal disorder associated with congenital 
diarrhea, steatorrhea, disruption of enterohepatic circulation of bile acids, and reduced plasma cholesterol levels (13). Consistent with previous findings, 728T $>C$ (Leu243Pro) or $785 \mathrm{C}>\mathrm{T}$ (Thr262Met) abolished bile acid transport activity but not total or cell surface protein expression of these variants.

To identify additional $S L C 10 A 2$ polymorphisms, we screened 360 ethnically-defined DNA samples. In agreement with other studies $(13 ; 19 ; 20 ; 25-27), S L C 10 A 2$ coding variants were rare and generally restricted by ethnicity except for the $511 \mathrm{G}>\mathrm{T}$ variant, which was identified in all ethnic populations and was relatively common in European-American samples ( $6 \%$ allele frequency). This is slightly less than previous studies in which the allele frequency of the $511 \mathrm{G}>\mathrm{T}$ variant was noted to range from $12.5-14 \%(19 ; 27 ; 28)$. The $292 \mathrm{G}>\mathrm{A}$ and $475 \mathrm{G}>\mathrm{A}$ variants had also been previously identified with similar low allele frequencies compared to our samples $(19 ; 27)$. The $431 \mathrm{G}>\mathrm{A}$ variant identified in this study appears to be novel.

Compared to wild-type ASBT, the $292 \mathrm{G}>\mathrm{A}$ and $431 \mathrm{G}>\mathrm{A}$ variants were associated with mild and moderately impaired transport function, respectively. Kinetic analysis revealed similar $K_{m}$ values for wild-type, $292 \mathrm{G}>\mathrm{A}$ and $431 \mathrm{G}>\mathrm{A}$ variants but modestly decreased intrinsic clearance $\left(V_{\max } / K_{m}\right)$ values for the $292 \mathrm{G}>\mathrm{A}$ (5-fold) and $431 \mathrm{G}>\mathrm{A}$ (8-fold) variants suggesting decreased taurocholate transport efficiency for these variants. Further analysis revealed similar protein expression and appropriate membrane trafficking for ASBT variants when compared to wild-type ASBT suggesting conformational changes in protein structure may be responsible for differences in transport efficiency associated with these variants. The results for $292 \mathrm{G}>\mathrm{A}$ are in agreement with previous work by Swaan and coworkers who showed that Cys144Ala is a loss of function mutation (29) and that this region of helix III functions as an important substrate exit route (30). A prior study had evaluated the $292 \mathrm{G}>\mathrm{A}$, $475 \mathrm{G}>\mathrm{A}$ and $511 \mathrm{G}>\mathrm{T}$ variants expressed in COS cells for bile acid transport function. Similar to this study, no significant differences in bile acid transport were observed for the $475 \mathrm{G}>\mathrm{A}$ or $511 \mathrm{G}>\mathrm{T}$ variants (27). However, the previous study found no significant difference in bile acid transport between the $292 \mathrm{G}>\mathrm{A}$ variant and wild-type ASBT. The reason for the discrepancy in results for the $292 \mathrm{G}>\mathrm{A}$ variant between our studies is not entirely clear but could be related to the different in vitro cell-based systems or times frames at which uptake was calculated. However, the finding that one of the subjects in the healthy normolipidemic control group in that study was homozygous for the $292 \mathrm{G}>\mathrm{A}$ variant suggests this variant has little effect on bile acid transport function in vivo (27).

In addition, we evaluated 4 previously identified SLC10A2 mutations. Not surprisingly, the $728 \mathrm{~T}>\mathrm{C}, 785 \mathrm{C}>\mathrm{T}$ and $868 \mathrm{C}>\mathrm{T}$ variants were associated with near complete loss of function for taurocholate transport, consistent with prior studies. The $790 \mathrm{~A}>\mathrm{G}$ variant also demonstrated near complete loss of taurocholate transport. These mutants are predicted to be located in transmembrane domains $6(728 \mathrm{~T}>\mathrm{C})$ and $7(868 \mathrm{C}>\mathrm{T})$ or extracellular domain 3 $(785 \mathrm{C}>\mathrm{T}, 790 \mathrm{~A}>\mathrm{G})$. The ASBT $868 \mathrm{C}>\mathrm{T}$ mutant is localized to transmembrane domain 7 and is highly conserved amongst members of the SLC10 family (31), supporting a critical role in transporter function. Additional studies support the roles of these regions in substrate recognition and transporter function. Using cysteine mutagenesis and thiol modification (SCAM), transmembrane domain 7 was identified as a critical component in forming part of the putative substrate translocation pathway (32). A subsequent similar analysis of transmembrane domain 6 supported a similarly important role in substrate translocation and that TM6 may cooperatively with TM7 to form a conformational switch that is requisite for bile acid substrate turnover (33). Clearly, this is a critical region of the ASBT where genetic variability is rare and not well tolerated with detrimental clinical consequences. 
Although prevalence of SNPs in SLC10A2 appear to be relatively infrequent, significant inter-individual variability in ASBT expression was noted in healthy adult individuals at the mRNA ( 11-fold) and protein ( 6-fold) levels. These findings are in agreement with previous studies of several cohorts including healthy subjects, gallstone carriers, and cholestatic patients $(34 ; 35)$ where a similar significant range of expression for ASBT mRNA and protein expression was noted. However in contrast to an earlier study of a cohort of women control subjects and gallstone carriers (34), we found no significant correlation between SLC1OA2 mRNA levels and ASBT protein expression. The reason for these differences is not clear, but may reflect differences in the biopsy site (duodenum versus ileum) or ethnic differences in the study populations.

In conclusion, we report the identification and functional characterization of nonsynonymous variants in $S L C 10 A 2$. Generally, variants were uncommon and tended to be ethnically-defined. The variants $292 \mathrm{G}>\mathrm{A}$ and $431 \mathrm{G}>\mathrm{A}$ were associated with impaired taurocholate function but the clinical impact on altered bile acid homeostasis is unclear and likely mitigated by the infrequent nature of these polymorphisms.

\section{Acknowledgments}

This work was supported by National Institutes of Health grants GM81363 (R.H.H.), GM54724 (R.B.K.), DK47987 (P.A.D.) and Program of Experimental Medicine (Dept of Medicine, University of Western Ontario). Confocal immunofluorescence microscopy experiments, data analysis, and presentation were performed in part through the use of the VUMC Cell Imaging Core Resource (supported by NIH grants CA68485, DK20593, DK58404, HD15052, DK59367, and EY08126).

\section{REFERENCES}

1. St-Pierre MV, Kullak-Ublick GA, Hagenbuch B, Meier PJ. Transport of bile acids in hepatic and non-hepatic tissues. J Exp Biol. 2001 May; 204(Pt 10):1673-1686. [PubMed: 11316487]

2. Trauner M, Boyer JL. Bile salt transporters: molecular characterization, function, and regulation. Physiol Rev. 2003 Apr; 83(2):633-671. [PubMed: 12663868]

3. Koop I, Schindler M, Bosshammer A, Scheibner J, Stange E, Koop H. Physiological control of cholecystokinin release and pancreatic enzyme secretion by intraduodenal bile acids. Gut. 1996 Nov; 39(5):661-667. [PubMed: 9026479]

4. Riepl RL, Fiedler F, Ernstberger M, Teufel J, Lehnert P. Effect of intraduodenal taurodeoxycholate and L-phenylalanine on pancreatic secretion and on gastroenteropancreatic peptide release in man. Eur J Med Res. 1996 Sep; 1(11):499-505. \%20. [PubMed: 9438149]

5. Keely SJ. Missing link identified: GpBAR1 is a neuronal bile acid receptor. Neurogastroenterol Motil. 2010 Jul; 22(7):711-717. [PubMed: 20553563]

6. Poole DP, Godfrey C, Cattaruzza F, Cottrell GS, Kirkland JG, Pelayo JC, et al. Expression and function of the bile acid receptor GpBAR1 (TGR5) in the murine enteric nervous system. Neurogastroenterol Motil. 2010 Jul; 22(7):814-818. [PubMed: 20236244]

7. Thomas C, Pellicciari R, Pruzanski M, Auwerx J, Schoonjans K. Targeting bile-acid signalling for metabolic diseases. Nat Rev Drug Discov. 2008 Aug; 7(8):678-693. [PubMed: 18670431]

8. Lefebvre P, Cariou B, Lien F, Kuipers F, Staels B. Role of bile acids and bile acid receptors in metabolic regulation. Physiol Rev. 2009 Jan; 89(1):147-191. [PubMed: 19126757]

9. Hylemon PB, Zhou H, Pandak WM, Ren S, Gil G, Dent P. Bile acids as regulatory molecules. J Lipid Res. 2009 Aug; 50(8):1509-1520. [PubMed: 19346331]

10. Hagenbuch B, Dawson P. The sodium bile salt cotransport family SLC10. Pflugers Arch. 2004 Feb; 447(5):566-570. [PubMed: 12851823]

11. Dawson PA, Lan T, Rao A. Bile acid transporters. J Lipid Res. 2009 Dec; 50(12):2340-2357. [PubMed: 19498215] 
12. Dawson PA, Haywood J, Craddock AL, Wilson M, Tietjen M, Kluckman K, et al. Targeted deletion of the ileal bile acid transporter eliminates enterohepatic cycling of bile acids in mice. $\mathbf{J}$ Biol Chem. 2003 Sep 5; 278(36):33920-33927. [PubMed: 12819193]

13. Oelkers P, Kirby LC, Heubi JE, Dawson PA. Primary bile acid malabsorption caused by mutations in the ileal sodium-dependent bile acid transporter gene (SLC10A2). J Clin Invest. 1997 Apr 15; 99(8):1880-1887. [PubMed: 9109432]

14. Craddock AL, Love MW, Daniel RW, Kirby LC, Walters HC, Wong MH, et al. Expression and transport properties of the human ileal and renal sodium-dependent bile acid transporter. Am J Physiol. 1998 Jan; 274(1 Pt 1):G157-G169. [PubMed: 9458785]

15. Weinman SA, Carruth MW, Dawson PA. Bile acid uptake via the human apical sodium-bile acid cotransporter is electrogenic. J Biol Chem. 1998 Dec 25; 273(52):34691-34695. [PubMed: 9856990]

16. Baringhaus KH, Matter H, Stengelin S, Kramer W. Substrate specificity of the ileal and the hepatic $\mathrm{Na}(+) /$ bile acid cotransporters of the rabbit. II. A reliable 3D QSAR pharmacophore model for the ileal $\mathrm{Na}(+)$ /bile acid cotransporter. J Lipid Res. 1999 Dec; 40(12):2158-2168. [PubMed: 10588941]

17. Kramer W, Stengelin S, Baringhaus KH, Enhsen A, Heuer H, Becker W, et al. Substrate specificity of the ileal and the hepatic $\mathrm{Na}(+)$ /bile acid cotransporters of the rabbit. I. Transport studies with membrane vesicles and cell lines expressing the cloned transporters. J Lipid Res. 1999 Sep; 40(9): 1604-1617. [PubMed: 10484607]

18. Johnson AD, Kavousi M, Smith AV, Chen MH, Dehghan A, Aspelund T, et al. Genome-wide association meta-analysis for total serum bilirubin levels. Hum Mol Genet. 2009 Jul 15; 18(14): 2700-2710. [PubMed: 19414484]

19. Renner O, Harsch S, Schaeffeler E, Winter S, Schwab M, Krawczyk M, et al. A variant of the SLC10A2 gene encoding the apical sodium-dependent bile acid transporter is a risk factor for gallstone disease. PLoS One. 2009 Oct 13.4(10):e7321. [PubMed: 19823678]

20. Renner O, Harsch S, Schaeffeler E, Schwab M, Klass DM, Kratzer W, et al. Mutation screening of apical sodium-dependent bile acid transporter (SLC10A2): novel haplotype block including six newly identified variants linked to reduced expression. Hum Genet. 2009 May; 125(4):381-391. [PubMed: 19184108]

21. Ho RH, Leake BF, Roberts RL, Lee W, Kim RB. Ethnicity-dependent polymorphism in Na+taurocholate cotransporting polypeptide (SLC10A1) reveals a domain critical for bile acid substrate recognition. J Biol Chem. 2004 Feb; 279(8):7213-7222. \%20. [PubMed: 14660639]

22. Wong MH, Oelkers P, Dawson PA. Identification of a mutation in the ileal sodium-dependent bile acid transporter gene that abolishes transport activity. J Biol Chem. 1995 Nov 10; 270(45):2722827234. [PubMed: 7592981]

23. Dawson, PA. Adolf Windau Lecture. Intestinal bile acid transport: Molecules, mechanism, and malabsorption. In: Paumgartner, G.; Stiehl, A.; Gerok, W.; Keppler, D.; Leuschner, U., editors. Falk Symposium 108: Bile Acids in Cholestasis; Boston: Kluwer Academic Publishers; 1999. p. $1-28$.

24. Dawson PA, Hubbert M, Haywood J, Craddock AL, Zerangue N, Christian WV, et al. The heteromeric organic solute transporter alpha-beta, Ostalpha-Ostbeta, is an ileal basolateral bile acid transporter. J Biol Chem. 2005 Feb 25; 280(8):6960-6968. [PubMed: 15563450]

25. Pan W, Song IS, Shin HJ, Kim MH, Choi YL, Lim SJ, et al. Genetic polymorphisms in Na(+)taurocholate co-transporting polypeptide (NTCP) and ileal apical sodium-dependent bile acid transporter (ASBT) and ethnic comparisons of functional variants of NTCP among Asian populations. Xenobiotica. 2011 Feb 22.

26. Montagnani M, Love MW, Rossel P, Dawson PA, Qvist P. Absence of dysfunctional ileal sodiumbile acid cotransporter gene mutations in patients with adult-onset idiopathic bile acid malabsorption. Scand J Gastroenterol. 2001 Oct; 36(10):1077-1080. [PubMed: 11589382]

27. Love MW, Craddock AL, Angelin B, Brunzell JD, Duane WC, Dawson PA. Analysis of the ileal bile acid transporter gene, SLC10A2, in subjects with familial hypertriglyceridemia. Arterioscler Thromb Vasc Biol. 2001 Dec; 21(12):2039-2045. [PubMed: 11742882] 
28. Wang W, Xue S, Ingles SA, Chen Q, Diep AT, Frankl HD, et al. An association between genetic polymorphisms in the ileal sodium-dependent bile acid transporter gene and the risk of colorectal adenomas. Cancer Epidemiol Biomarkers Prev. 2001 Sep; 10(9):931-936. [PubMed: 11535543]

29. Banerjee A, Ray A, Chang C, Swaan PW. Site-directed mutagenesis and use of bile acid-MTS conjugates to probe the role of cysteines in the human apical sodium-dependent bile acid transporter (SLC10A2). Biochemistry. 2005 Jun 21; 44(24):8908-8917. [PubMed: 15952798]

30. Hussainzada N, Claro Da ST, Swaan PW. The cytosolic half of helix III forms the substrate exit route during permeation events of the sodium/bile acid cotransporter ASBT. Biochemistry. 2009 Sep 15; 48(36):8528-8539. [PubMed: 19653651]

31. Geyer J, Wilke T, Petzinger E. The solute carrier family SLC10: more than a family of bile acid transporters regarding function and phylogenetic relationships. Naunyn Schmiedebergs Arch Pharmacol. 2006 Mar; 372(6):413-431. [PubMed: 16541252]

32. Hussainzada N, Banerjee A, Swaan PW. Transmembrane domain VII of the human apical sodiumdependent bile acid transporter ASBT (SLC10A2) lines the substrate translocation pathway. Mol Pharmacol. 2006 Nov; 70(5):1565-1574. [PubMed: 16899538]

33. Hussainzada N, Khandewal A, Swaan PW. Conformational flexibility of helix VI is essential for substrate permeation of the human apical sodium-dependent bile acid transporter. Mol Pharmacol. 2008 Feb; 73(2):305-313. [PubMed: 17971420]

34. Bergheim I, Harsch S, Mueller O, Schimmel S, Fritz P, Stange EF. Apical sodium bile acid transporter and ileal lipid binding protein in gallstone carriers. J Lipid Res. 2006 Jan; 47(1):42-50. [PubMed: 16237211]

35. Hruz P, Zimmermann C, Gutmann H, Degen L, Beuers U, Terracciano L, et al. Adaptive regulation of the ileal apical sodium dependent bile acid transporter (ASBT) in patients with obstructive cholestasis. Gut. 2006 Mar; 55(3):395-402. [PubMed: 16150853] 


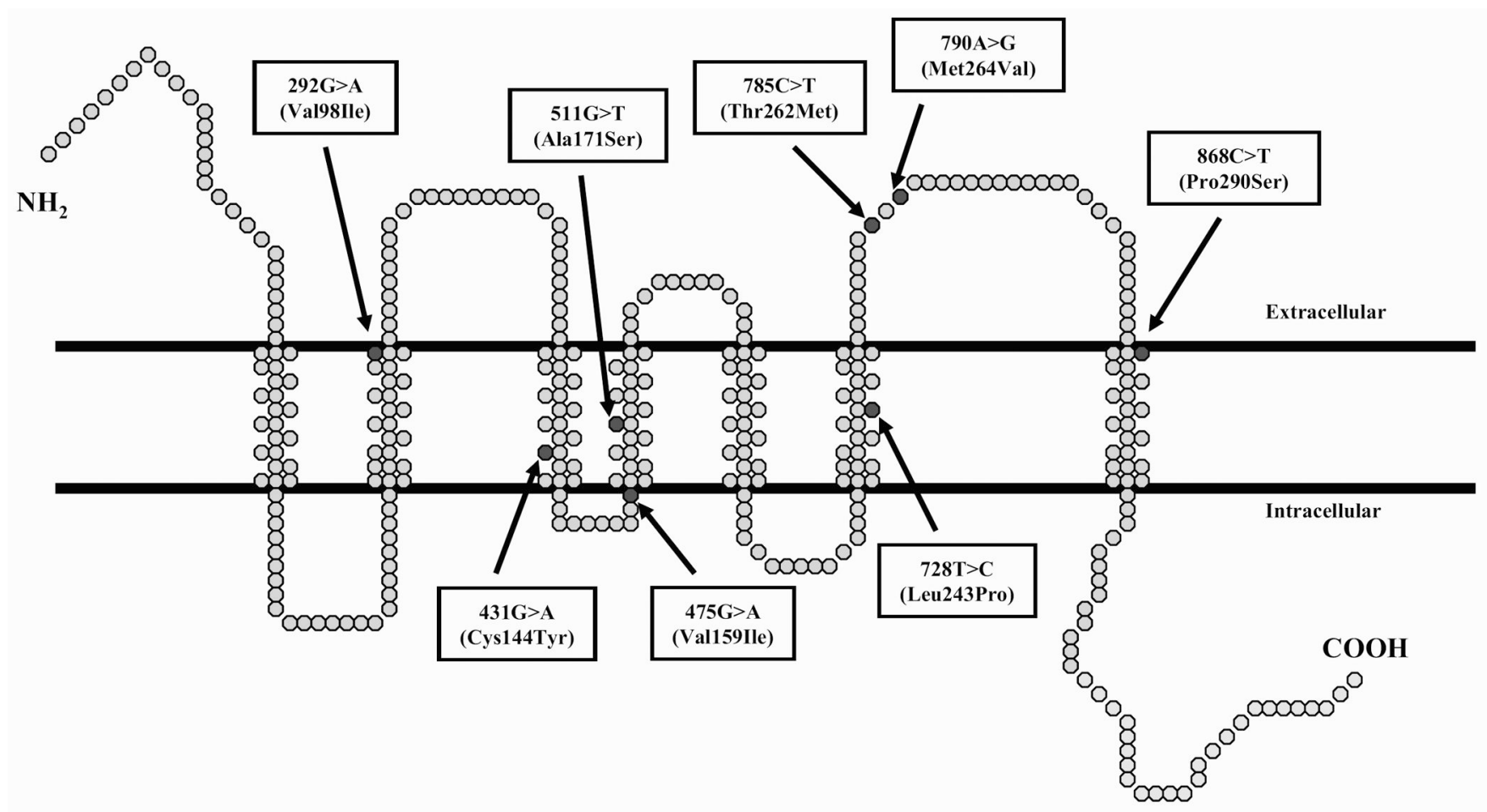

Figure 1. Schematic representation of ASBT and location of coding region single nucleotide polymorphisms

Schematic transmembrane topology is based on amino acid sequence analysis using PredictProtein (http://www.predictprotein.org) and published ASBT models. The location of nonsynonymous nucleotide substitutions and dysfunctional bile acid transporter mutations in SLC10A2 are indicated with arrows. 
A.

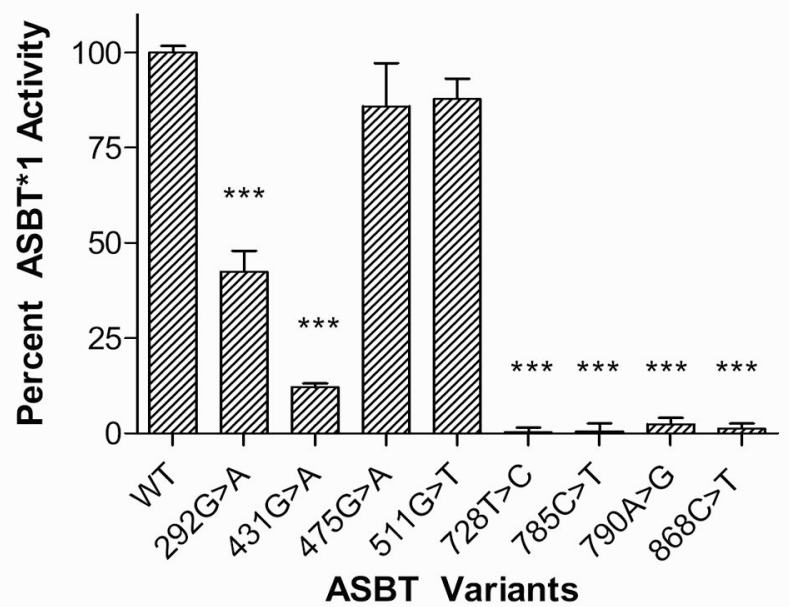

B.
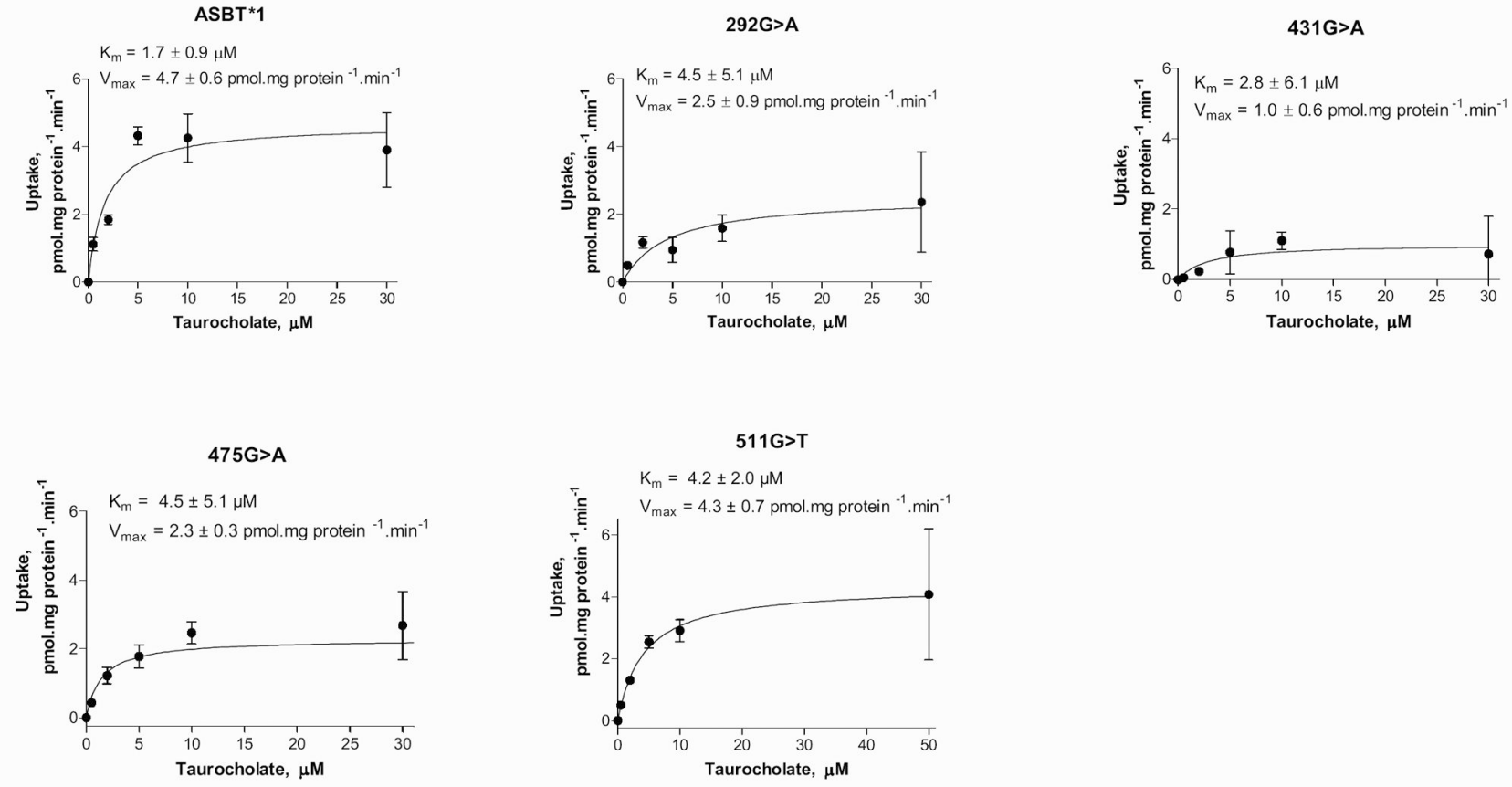

Figure 2. Taurocholate uptake and transport kinetics by ASBT variants

A, $\left[{ }^{3} \mathrm{H}\right]$ taurocholate $(5 \mu \mathrm{M})$ uptake at 10 min expressed as percentage of $S L C 10 A 2 * 1$ (wildtype) activity (mean $\pm \mathrm{SE}, \mathrm{n}=4)$. $* * * \mathrm{p}<0.001$ relative to $\mathrm{ASBT}^{*} 1$. B, Concentrationdependent uptake of taurocholate at $5 \mathrm{~min}$ by wild-type ASBT and the indicated variants $(292 \mathrm{G}>\mathrm{A}, 431 \mathrm{G}>\mathrm{A}, 475 \mathrm{G}>\mathrm{A}$ and $511 \mathrm{G}>\mathrm{T})$. Kinetic parameters were obtained by non-linear curve fitting. 
Total Protein
Anti-ASBT

\section{Anti-Calnexin}
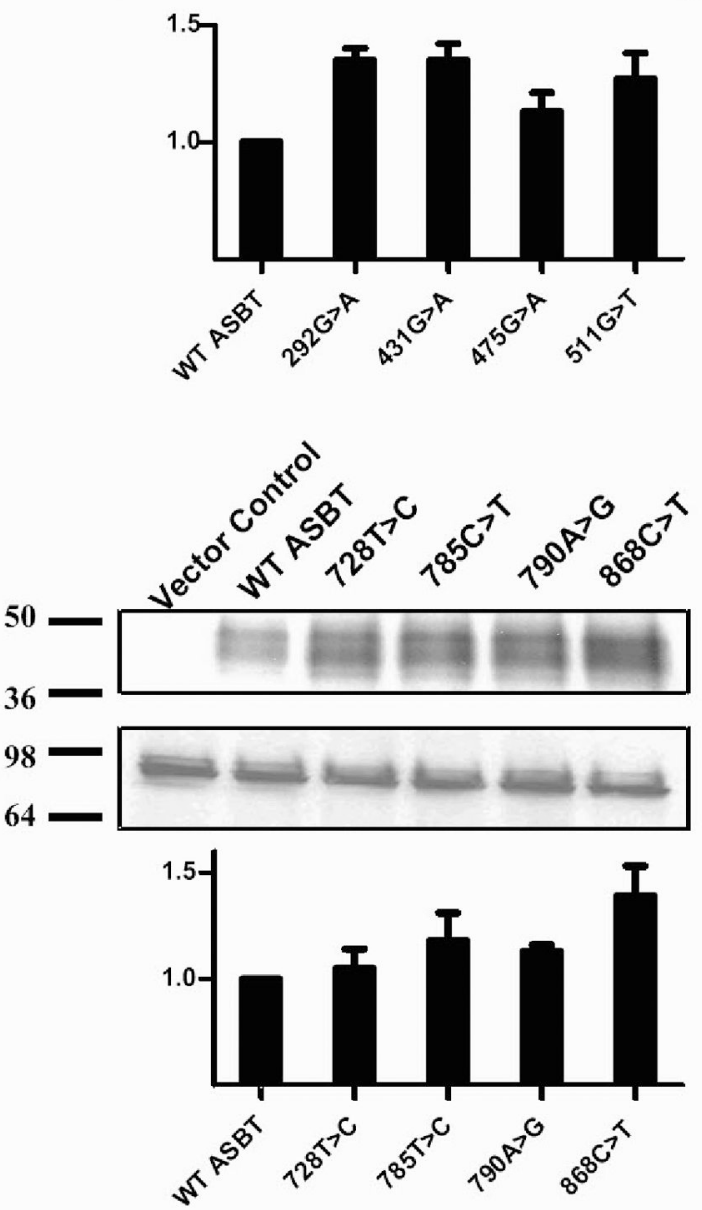

Anti-ASBT

Anti-Calnexin

\section{Cell Surface}
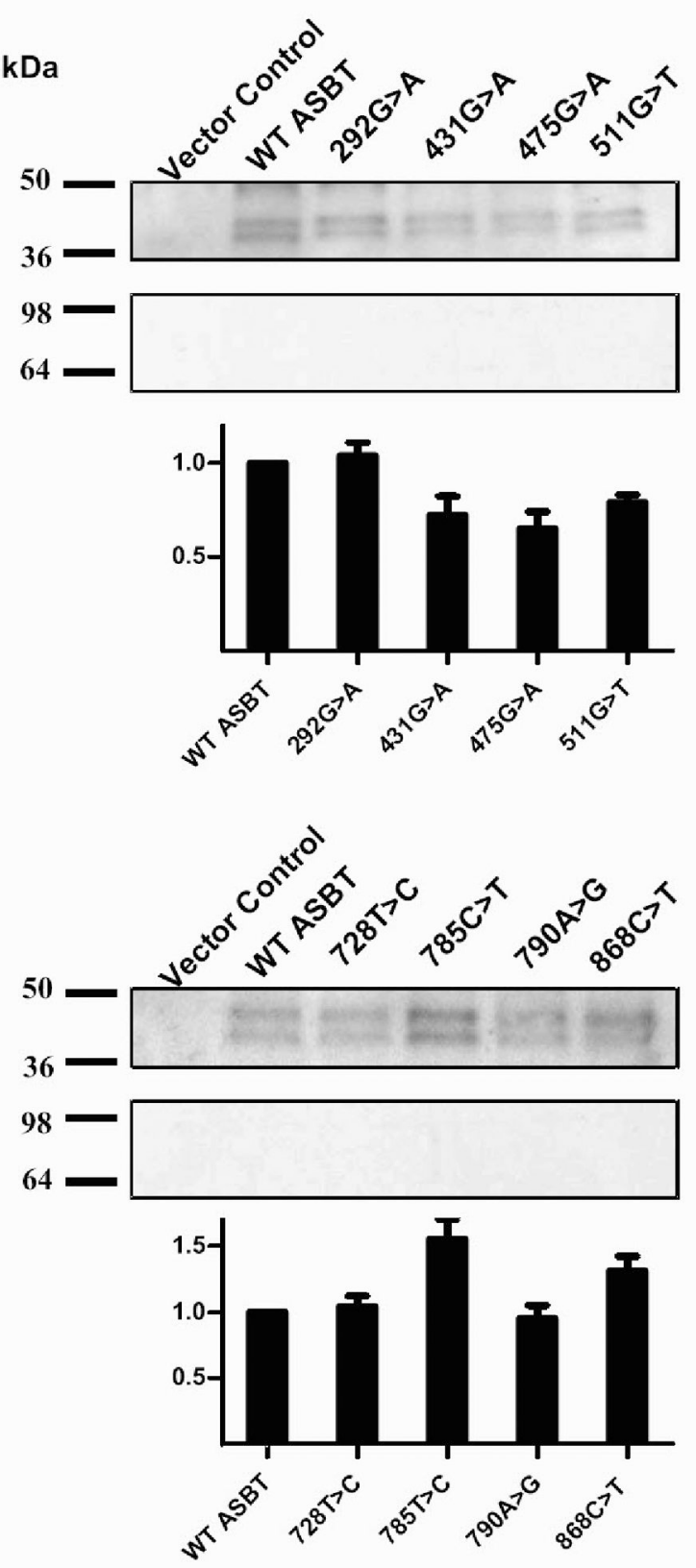

Figure 3. Total and cell surface protein expression of wild-type and variant ASBT Total HeLa cell lysates containing both biotinylated and non-biotinylated proteins (left panels) and cell surface proteins (captured on streptavidin beads) (right panels) were subjected to SDS-PAGE and transferred onto nitrocellulose. Immunoblots were probed with anti-ASBT antibody (top panels), then stripped and probed with anti-calnexin antibody (bottom panels). Relative protein expression was quantified with wild-type ASBT as reference and normalized to calnexin expression. 


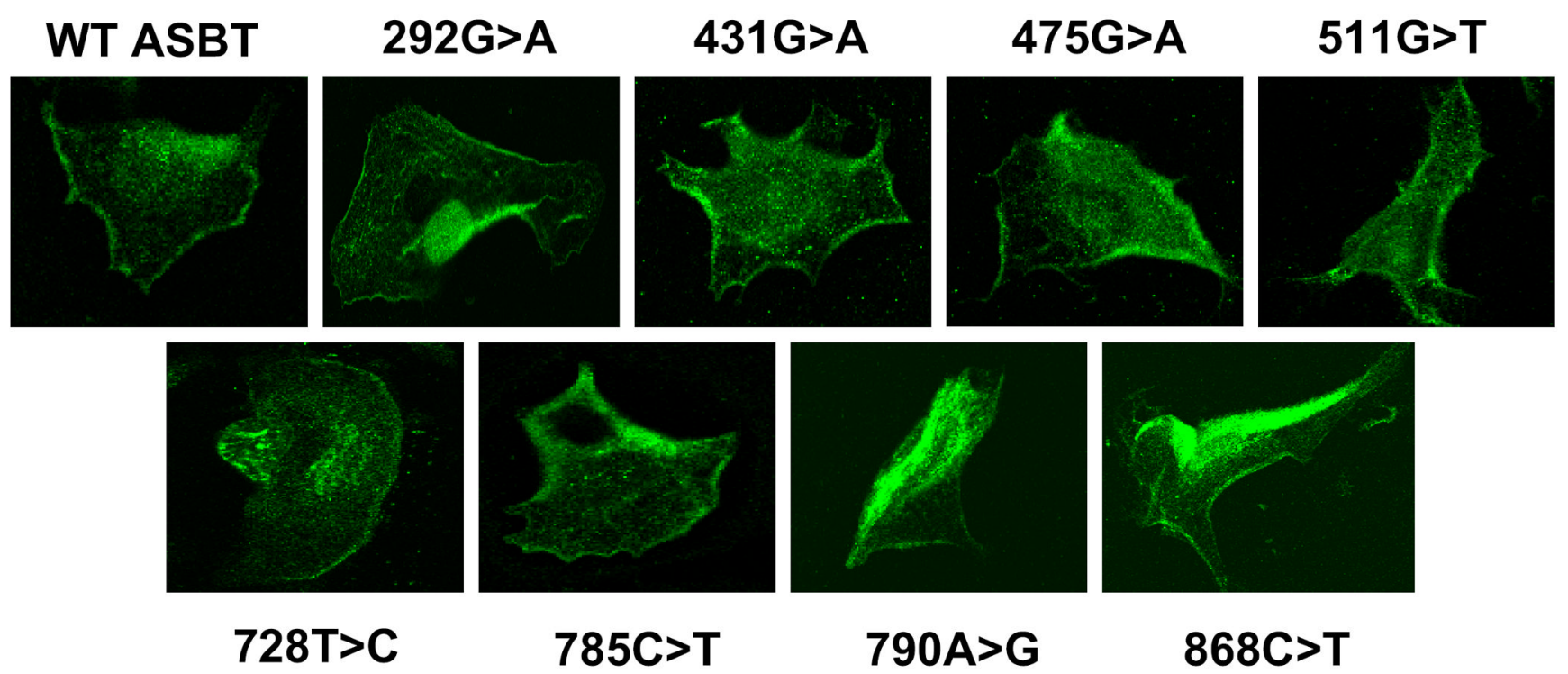

Figure 4. Immunofluorescence confocal microscopy of ASBT variants in HeLa cells Immunofluorescent-labeled secondary antibody (Alexa Fluor 488) was used to detect ASBT variants. Wild-type ASBT (top left panel) was targeted to the cell surface in as demonstrated by lateral ( $x-y$ scan) confocal imaging across the cell. All ASBT variants, including the mutations associated with $\mathrm{PBAM}, 728 \mathrm{~T}>\mathrm{C}$ and $785 \mathrm{C}>\mathrm{T}$, demonstrate appropriate targeting of ASBT to the plasma membrane. 
A.

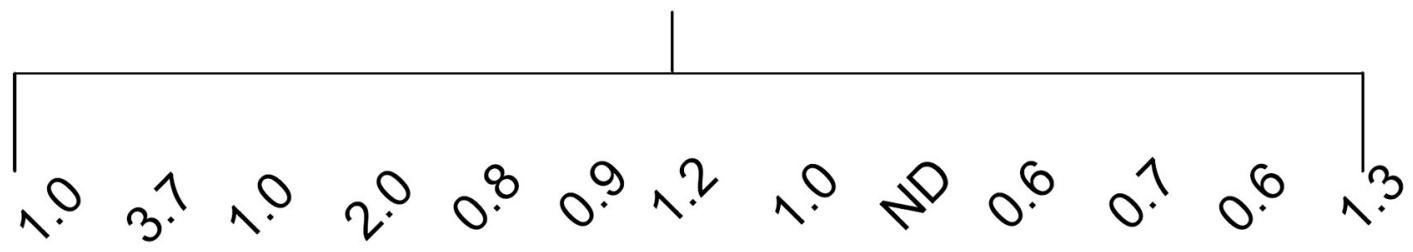

ASBT

Villin

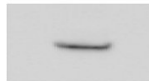

B.

C.
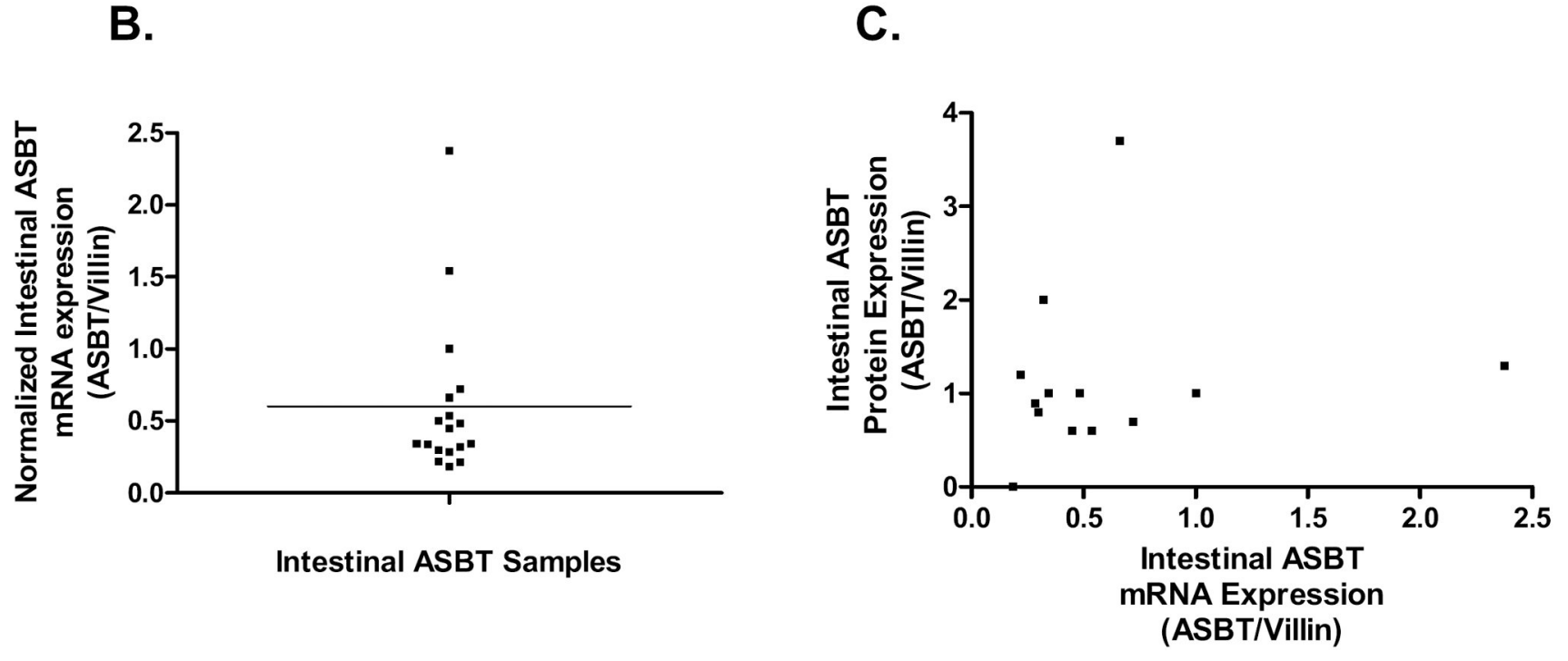

Figure 5. Protein and mRNA analysis of ASBT from human intestinal samples A, Inter-individual variation in ASBT protein expression from human duodenal samples is demonstrated using anti-ASBT antibody (top panel). Samples were normalized for loading using anti-villin antibody (bottom panel). B, Semiquantitative ASBT mRNA analysis was performed on human intestinal samples, normalized to villin expression. $\mathbf{C}$, Scatter plot of mRNA copy number versus densitometric units for ASBT. ND, not determined. 
Table 1

Allele frequencies of single nucleotide polymorphisms in SLC10A2 among various ethnic populations (European-, African- Chinese-, and Hispanic-Americans; $n=90$ for each ethnic group).

\begin{tabular}{|c|c|c|c|c|c|c|}
\hline \multirow[b]{2}{*}{ SNP } & \multirow[b]{2}{*}{ Exon } & \multirow[b]{2}{*}{ Amino Acid Change } & \multirow[b]{2}{*}{ European-Am } & \multicolumn{2}{|c|}{ Allele Frequencies (\%) } & \multirow[b]{2}{*}{ Hispanic-Am } \\
\hline & & & & African-Am & Chinese-Am & \\
\hline $292 \mathrm{G}>\mathrm{A}$ & 1 & Val98Ile & 2.2 & 1.1 & none & 1.1 \\
\hline $429 \mathrm{G}>\mathrm{C}$ & 2 & Leu143Leu & none & none & 0.5 & none \\
\hline $431 \mathrm{G}>\mathrm{A}$ & 2 & Cys144Tyr & 0.5 & none & none & none \\
\hline $475 \mathrm{G}>\mathrm{A}$ & 2 & Val159Ile & 1.6 & 1.1 & none & 0.5 \\
\hline $511 \mathrm{G}>\mathrm{T}$ & 3 & Ala171Ser & 6.0 & 1.7 & 4.5 & 3.9 \\
\hline $516 \mathrm{C}>\mathrm{T}$ & 3 & Leu172Leu & none & 1.1 & none & none \\
\hline $728 \mathrm{~T}>\mathrm{C}^{\dagger}$ & 4 & Leu243Pro & \multicolumn{3}{|c|}{ PBAM mutation (loss of function) } & \\
\hline $785 \mathrm{C}>\mathrm{T}^{\dagger}$ & 5 & Thr262Met & \multicolumn{3}{|c|}{ PBAM mutation (loss of function) } & \\
\hline $790 \mathrm{~A}>\mathrm{G}^{+}$ & 5 & Met264Val & \multicolumn{2}{|l|}{ rare } & & \\
\hline $868 \mathrm{C}>\mathrm{T} \S$ & 5 & Pro290Ser & \multicolumn{2}{|l|}{ rare } & & \\
\hline \multicolumn{7}{|c|}{ Previously identified (13) } \\
\hline \multicolumn{7}{|c|}{${ }^{*}$ Previously identified (23) } \\
\hline
\end{tabular}

